\title{
High-Performance Liquid Chromatographic Determination of Iron-Containing Proteins with On-Line Inductively Coupled Plasma Mass Spectrometric Detection
}

\author{
Kikuo Takatera and Tadashi Watanabe \\ Institute of Industrial Science, University of Tokyo, Roppongi, Minato, Tokyo 106, Japan
}

\begin{abstract}
An inductively coupled plasma mass spectrometer was employed as an iron detector in gel permeation liquid chromatography to separate ferritin, hemoglobin, myoglobin, and cytochrome- $c$, by use of potassium hexacyanoferrate(III) as the iron standard. The absolute detection limits for the four proteins were $0.01,1,0.7$, and $0.4 \mu \mathrm{g}$, respectively, at $10 \mu \mathrm{l}$ injections. These values were an order-of-magnitude lower than those obtained by using an inductively coupled plasma atomic emission spectrometer as detector. From the peak area in the Fe chromatograms, the number of $\mathrm{Fe}$ atoms per molecule was evaluated for myoglobin and cytochrome- $c$ to be 0.97 and 1.0, respectively.
\end{abstract}

Keywords Inductively coupled plasma mass spectrometry, high-performance gel permeation liquid chromatography, iron-containing protein

Iron is a biologically essential element, and the metabolic importance of iron depends heavily on its chemical form. ${ }^{1}$ Many iron-containing biological molecules are iron-proteins; their metabolism has been studied by use of radioactive ${ }^{55} \mathrm{Fe}$ and ${ }^{59} \mathrm{Fe}$. The recently introduced inductively coupled plasma mass spectrometry (ICP/MS) features highly sensitive, metalspecific analysis of metalloproteins without the need to use radioactive tracers. On the other hand, high performance liquid chromatography (HPLC) is now commonly used in the analysis of biological samples. Thus it is a logical consequence to use ICP/MS as an element-specific detector, in place of non-specific refractive index or ultraviolet detectors for HPLC. ${ }^{2-15}$ For biological macromolecules, gel permeation chromatographic (GPC) columns are generally used to separate the compounds according to the size.

Most studies on the HPLC-ICP/MS system have focused on improving the sensitivity of detecting metalcontaining compounds; these studies rarely provide information about their absolute quantitation efficiency. This is especially the case when a GPC column is used to separate various proteins, because the result tends to suffer from poor protein recovery caused by adsorption of proteins on the stainless steel tubing of the GPC column $^{16}$, and also from an ICP/MS instrumental instability due to the clogging on the plasma torch, sampling corn, or skimmer corn by inorganic salts accompanying biological samples.

In the present work we examined the feasibility of using ICP/MS as a metal detector for high performance GPC for quantifying metalloproteins. Iron was chosen as the metal because of its biological importance and in view of a need to assess the practical sensitivity for this element, since it has mass numbers $(54-58)$ in a range where a strong interference from the background molecular ions generally occurs. No such work has ever been reported on the metalloproteins (ferritin, hemoglobin, myoglobin, and cytochrome-c) selected here.

\section{Experimental}

\section{Materials}

All common chemicals and solvents were of reagent grade. Ferritin (Type I, from horse spleen), myoglobin (Type I, from horse skeletal muscle; assay 95-100\%) and cytochrome- $c$ (Type III, from horse heart; assay 95 $100 \%$ ) were obtained from Sigma, hemoglobin (from bovine blood; assay min. 80\%) from Wako Pure Chemical Industries, Ltd., and $\mathrm{K}_{3}\left[\mathrm{Fe}(\mathrm{CN})_{6}\right]$ from Koso Chemical Co., Ltd. These were used without further purification. A pH 7.0 tris(hydroxymethyl)aminomethane(Tris)-HCl buffer $(0.05 \mathrm{M})$ and water deionized with a Milli-Q system (Millipore Filter Co. Ltd.) were used throughout the experiments.

\section{Apparatus and procedures}

The HPLC system was composed of a JASCO 880-PU dual piston HPLC pump, a Rheodyne 7125 injector, and a JASCO $870-U V /$ vis detector set at $254 \mathrm{~nm}$. The column employed was Du Pont GF-250 (250 $\mathrm{mm} \times$ $9.4 \mathrm{~mm}$ i.d.). High performance gel permeation 
Table 1 ICP/MS and ICP/AES operating conditions

\begin{tabular}{|c|c|c|}
\hline \multicolumn{3}{|l|}{ ICP/MS } \\
\hline \multirow[t]{2}{*}{ Rf power } & forward & $1.2 \mathrm{~kW}$ \\
\hline & reflected & $<5 \mathrm{~W}$ \\
\hline \multirow[t]{3}{*}{ Gas flow rate } & coolant & $181 \min ^{-1}$ \\
\hline & auxiliary & $1.01 \mathrm{~min}^{-1}$ \\
\hline & nebulizer & $1.21 \mathrm{~min}^{-1}$ \\
\hline Spray chamber & \multicolumn{2}{|c|}{$\begin{array}{l}\text { Scott-type double pass } \\
\text { water cooled, } 15^{\circ} \mathrm{C}\end{array}$} \\
\hline Nebulizer & \multicolumn{2}{|c|}{ Meinhard TR-30-C2 } \\
\hline Sampling cone & \multicolumn{2}{|c|}{$\mathrm{Cu}$ with $1.1-\mathrm{mm}$ diameter orifice } \\
\hline \multicolumn{3}{|l|}{ ICP/AES } \\
\hline \multirow[t]{2}{*}{ Rf power } & forward & $1.3 \mathrm{~kW}$ \\
\hline & reflected & $<5 \mathrm{~W}$ \\
\hline \multirow[t]{3}{*}{ Gas flow rate } & coolant & $161 \mathrm{~min}^{-1}$ \\
\hline & auxiliary & $0.531 \mathrm{~min}^{-1}$ \\
\hline & nebulizer & $0.95 \min ^{-1}$ \\
\hline
\end{tabular}

chromatography was performed under the following conditions: eluent, $0.2 \mathrm{M}$ ammonium sulfate $\left(\left(\mathrm{NH}_{4}\right)_{2} \mathrm{SO}_{4}\right)$ and $0.05 \mathrm{M}$ Tris-HCl buffer ( $\mathrm{pH} \mathrm{7.0);} \mathrm{flow} \mathrm{rate,}$ $1.0 \mathrm{ml} \mathrm{min}^{-1}$; and temperature, $23^{\circ} \mathrm{C}$. Ten microliters of each sample solution was injected to the column.

The final end of the HPLC system, namely the outlet of the $\mathrm{UV} / \mathrm{vis}$ detector, was directly connected to the nebulizer of an ICP/MS (Seiko Instrument Inc. SPQ6100) or ICP/AES (Seiko Instrument Inc. SPS$1200 \mathrm{VR})$. The ICP/MS and ICP/AES operating conditions are given in Table 1. In the ICP/MS measurement, the mass spectrometer was operated in a sequential measurement mode, where the measurements are made by spending a total measurement time of $0.1 \mathrm{~s}$ at one mass before going to the next. Within the total measurement time, three data acquisitions were done per peak, one at the central mass while the other two at \pm 0.125 a.u. from the assumed center. These were repeated until all of the components were eluted out. In the ICP/AES measurement, the iron emission line at $238.204 \mathrm{~nm}$ was monitored.

\section{Results and Discussion}

\section{HPLC-ICP/MS instrumental stability}

Proper selection of the mobile phase is one of the most crucial problems in the HPLC-ICP/MS measurement, especially with biological samples which are often accompanied by a buffer. The use of buffers containing an alkali metal cation, sodium phosphate buffer $(0.2 \mathrm{M})$ for example, gave rise to gradual salt clogging of the sampler, skimmer and plasma torch injector. This caused a serious instrumental drift in minutes after nebulizing the buffer into the quadrupole mass spectrometer, and consequently rendered the determination of proteins impossible. This was neatly overcome by use of a Tris- $\mathrm{HCl}$ buffered mobile phase with $0.2 \mathrm{M}$ ammonium sulfate added. This procedure yielded a
Table 2 HPLC-ICP/MS absolute (Abs, ng) and relative (Rel, $\left.\mu \mathrm{g} \mathrm{l}^{-1}\right)$ detection limits $(3 \sigma)$ for iron ${ }^{\mathrm{a}}$

\begin{tabular}{cccc}
\hline $\begin{array}{c}\text { Isotope } \\
\text { (Abundance, } \%)\end{array}$ & $\begin{array}{c}\text { Blank/ } \\
\text { counts s }\end{array}$ & $\begin{array}{c}\text { Abs/ } \\
\text { ng }\end{array}$ & $\begin{array}{c}\text { Rel/ } \\
\mu \mathrm{g} \mathrm{l}^{-1}\end{array}$ \\
\hline${ }^{54} \mathrm{Fe}(5.8)$ & 400 & 2 & 200 \\
${ }^{56} \mathrm{Fe}(91.7)$ & 5000 & 1 & 100 \\
${ }^{57} \mathrm{Fe}(2.2)$ & 100 & 2 & 200 \\
${ }^{58} \mathrm{Fe}(0.3)$ & 1000 & 30 & 3000 \\
\hline
\end{tabular}

a. Sample, $\mathrm{K}_{3}\left[\mathrm{Fe}(\mathrm{CN})_{6}\right]$; injection, $10 \mu \mathrm{l}$.

quantitative protein recovery (see below). Although no salt built up on the sampler and skimmer, a gradual clogging of the plasma torch injector was noted. Regular cleaning of the plasma torch for approximately $3 \mathrm{~h}$ after nebulizing the buffer into the mass spectrometer, however, well suppressed any significant instrumental drift.

\section{Mass number dependence of detection limits}

In the ICP/MS spectra of eluent of the HPLC system, several molecular ions ( $\mathrm{ArN}^{+}, \mathrm{ArNH}^{+}, \mathrm{ArO}^{+}, \mathrm{ArOH}^{+}$) arising from the atmosphere, eluent buffer, and argon plasma manifested themselves in the region of iron isotope mass number from 54 to 58 . Since these background signals affect the detection limit of iron, appropriate selection of the mass number is important for measurements attempted in this work. This feature has been examined first by use of $\mathrm{K}_{3}\left[\mathrm{Fe}(\mathrm{CN})_{6}\right]$ as sample.

Table 2 shows the background ion counts and the detection limits of iron measured at a series of iron isotope mass numbers. The detection limits, defined as that amount of analyte yielding a net signal equivalent to three standard deviations ( $3 \sigma)$ of the background, were calculated for the four stable isotopes of iron in the multielement mode. The detection limit of iron depends on the relative natural abundance and the background level at each mass number. Of the four isotopes, ${ }^{56} \mathrm{Fe}$ showed the lowest detection limit. However, due to the high background at this mass number, identical with that of argon oxide $\left({ }^{40} \mathrm{Ar}^{16} \mathrm{O}^{+}\right)$, the detection limit is relatively high in spite of its high relative abundance. These detection limit values are almost comparable to those obtained by Janghorbani et al. using direct nebulization of sample solutions in the ICP/MS measurements. ${ }^{17}$

HPLC can remove on-line a troublesome matrix in the ICP/MS measurement. ${ }^{4}$ In ordinary ICP/MS measurements for the determination of ${ }^{56} \mathrm{Fe}$, special attention should be paid to the interference by ${ }^{40} \mathrm{Ca}^{16} \mathrm{O}^{+}$, in cases where a calcium salt is contained in the sample solution. In the HPLC-ICP/MS measurement, however, free $\mathrm{Ca}^{2+}$ ion is eluted out separately after the iron-containing proteins. Such is the most salient feature of the HPLC-ICP/MS combined measurement system. 
Table 3 Properties and HPLC-ICP/MS absolute (Abs, $\mu \mathrm{g}$ ) and relative ( $\mathrm{Rel}, \mathrm{mg} \mathrm{l}^{-1}$ ) detection limits $(3 \sigma)$ for ironcontaining proteins $\mathrm{s}^{\mathrm{a}}$

\begin{tabular}{lrcccr}
\hline \multicolumn{1}{c}{ Protein } & MW & $\begin{array}{c}\text { Fe content } / \\
\text { mol }\end{array}$ & $\begin{array}{c}t_{\mathrm{r}} \mathrm{b}^{2} \\
\mathrm{~s}\end{array}$ & $\begin{array}{c}\mathrm{Abs} / \\
\mu \mathrm{g}\end{array}$ & $\begin{array}{r}\mathrm{Rel} / \\
\mathrm{mg} \mathrm{l}^{-1}\end{array}$ \\
\hline Ferritin & 460000 & ca. 2000 & 480 & 0.01 & 1 \\
Hemoglobin & 67000 & 4 & 610 & 1 & 100 \\
Myoglobin & 16800 & 1 & 640 & 0.7 & 70 \\
Cytochrome- $c$ & 12384 & 1 & 660 & 0.4 & 40 \\
\hline
\end{tabular}

a. At mass number 56 ; injection, $10 \mu \mathrm{l}$.

b. Retention time.

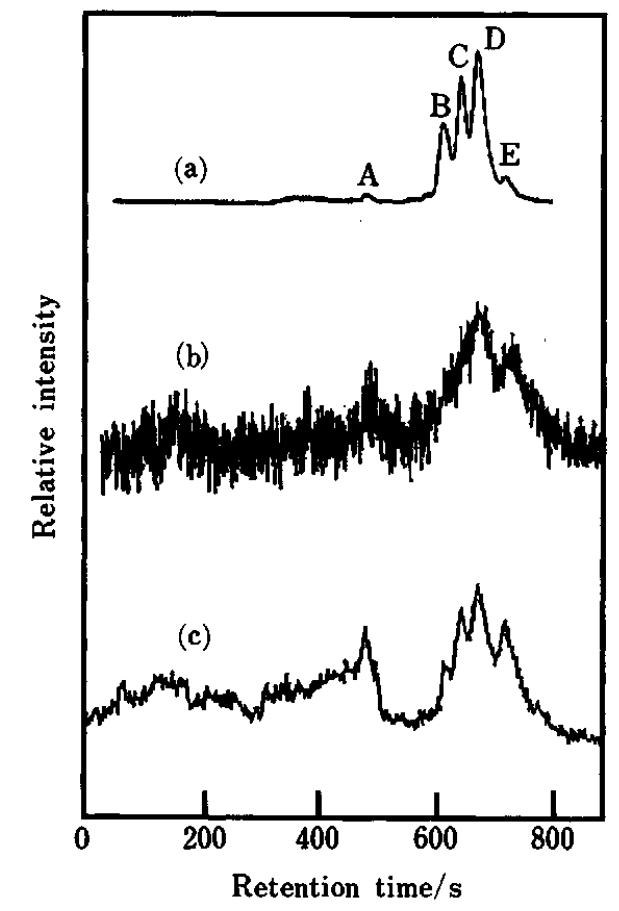

Fig. 1 HPLC traces for metalloproteins [ferritin $(0.02 \mu \mathrm{g})$ (A), hemoglobin $(2 \mu \mathrm{g})(\mathrm{B})$, myoglobin $(2 \mu \mathrm{g})(\mathrm{C})$, and cytochrome- $c(2 \mu \mathrm{g})(\mathrm{D})]$ and $\mathrm{K}_{3}\left[\mathrm{Fe}(\mathrm{CN})_{6}\right](0.0067 \mu \mathrm{g}$ as $\mathrm{Fe})$ (E) by (a) UV/vis (254 nm), (b) ICP/AES (238.204 nm) and (c) ICP/MS $\left({ }^{56} \mathrm{Fe}\right)$ detection.

\section{Detection limits of iron-containing proteins}

In gel permeation chromatography, proteins are eluted in the descending order of molecular weight. For the four iron-containing proteins, the molecular weight, number of $\mathrm{Fe}$ atoms per molecule, and the detection limits in the present measurement system are summarized in Table 3. In calculating the detection limits, the purity of each protein was assumed to be $100 \%$. Iron was monitored at mass number 56 . As might be expected, the detection limit became lower as the iron content per molecular weight became higher.

The chromatograms recorded with the three detectors (UV, ICP/MS and ICP/AES) are displayed in Fig. 1. The detection limits with ICP/MS were about an order-

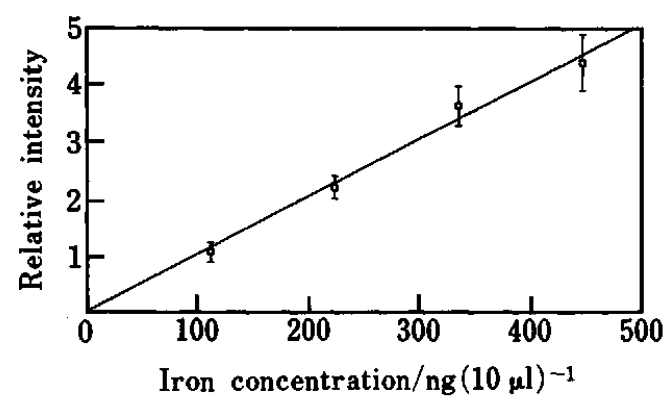

Fig. 2 Calibration graph for $\mathrm{K}_{3}\left[\mathrm{Fe}(\mathrm{CN})_{6}\right]$. Each data point denotes mean $\pm 2 \sigma$ of five consecutive measurements.

of-magnitude lower than those found with ICP/AES. Though the UV detector gave the lowest detection limits, it gives no information about the iron content. The ICP/MS (and ICP/AES) traces are neatly broader than the UV trace, mainly due to a larger effective cell volume and longer measurement time constants. ${ }^{2}$ The Scotttype double pass spray chamber of ICP/MS has roughly three orders-of-magnitude greater volume than the HPLC transport lines and therefore needs a longer cleanout time.

\section{Precision and linearity}

The precision of iron determination was studied as a function of concentration. Aqueous solutions containing $\mathrm{K}_{3}\left[\mathrm{Fe}(\mathrm{CN})_{6}\right]$ were prepared at four concentration levels in the buffer matrix and then analyzed consecutively five times to calculate standard deviations. An overall linear least-squares fit to the peak area $v s$. concentration profile is presented in Fig. 2, demonstrating a linear response and a precision of better than $10 \%$ in a concentration range of $112-448 \mathrm{ng} / 10 \mu \mathrm{l}$.

\section{Determination of iron content in proteins}

The detection limit data for the iron-containing proteins presented above (Table 3) are based on the weight of proteins injected to the HPLC column. If the injected protein is totally eluted out from the column, namely if the recovery is quantitative, the peak area in the ICP/MS chromatogram should give the amount of $\mathrm{Fe}$ atoms per molecule in accordance with the theoretical value. This point has been examined by choosing myoglobin and cytochrome- $c$, each containing one $\mathrm{Fe}$ atom per molecule, and for which we could reasonably assume a purity of $100 \%$ (see above). Five independent runs gave the $\mathrm{Fe} /$ protein molar ratio of $0.97 \pm 0.05$ and $1.0 \pm 0.1$ for myoglobin and cytochrome-c, respectively, which are close to the theoretical value of 1 . These results ensure a quantitative recovery of the two proteins in the present HPLC-ICP/MS setup. The good recovery and the good instrumental stability of the present system come from a proper choice of the HPLC mobile phase, and would be promising in future investigations on the metal metabolic processes in vivo. ${ }^{18}$ 
This work was supported in part by a Grant-in-Aid for Scientific Research (No.02202212) from the Ministry of Education, Science and Culture.

\section{References}

1. T. H. Bothwell, R. W. Charlton, J. D. Cook and C. A. Finch, "Iron Metabolism in Man", Blackwell Scientific, Oxford, 1979.

2. J. R. Dean, S. Munro, L. Ebdon, H. M. Crews and R. C. Massey, J. Anal. At. Spectrom., 2, 607 (1987).

3. H. M. Crews, J. R. Dean, L, Ebdon and R. C. Massey, Analyst [London], 114, 895 (1989).

4. B. S. Sheppard, W. L. Shen, J. A. Caruso, D. T. Heitkemper and F. L. Fricke, J. Anal. At. Spectrom., 5, 431 (1990).

5. J. J. Thompson and R. S. Houk, Anal. Chem., 58, 2541 (1986).

6. D. S. Bushee, Analyst [London], 113, 1167 (1988).

7. S. J. Jiang and R. S. Houk, Spectrochim. Acta, 43B, 405 (1988).

8. D. Beauchemin, M. E. Bednas, S. S. Berman, J. W. McLaren, K. W. M. Siu and R. E. Sturgeon, Anal. Chem., 60, 2209 (1988).
9. H. Suyani, J. Creed, T. Davidson and J. Caruso, J. Chromatogr. Sci., 27, 139 (1989).

10. H. Suyani, D. Heitkemper, J. Creed and J. Caruso, Appl. Spectrosc., 43, 967 (1989).

11. D. Beauchemin, K. W. M. Siu, J. W. McLaren and S. S. Berman, J. Anal. At. Spectrom., 4, 285 (1989).

12. D. Heitkemper, J. Creed, J. Caruso and F. L. Fricke, $J$. Anal. At. Spectrom., 4, 279 (1989).

13. S. G. Matz, R. C. Elder and K. Tepperman, J. Anal. At. Spectrom., 4, 767 (1989).

14. D. S. Bushee, J. R. Moody and J. C. May, J. Anal. At. Spectrom., 4, 773 (1989).

15. J. W. McLaren, K. W. M. Siu, J. W. Lam, S. N. Willie, P. S. Maxwell, A. Palepu, M. Koether and S. S. Berman, Fresenius' J. Anal. Chem., 337, 721 (1990).

16. M. Morita, T. Uehiro and K. Fuwa, Anal. Chem., 52, 349 (1980).

17. M. Janghorbani and B. T. G. Ting, "Application of Inductively Coupled Plasma Mass Spectrometry”, ed. A. R. Date and A. L. Gray, p. 115, Blackie, 1989.

18. P. G. Whittaker, T. Lind, J. G. Williams and A. L. Gray, Analyst [London], 114, 675 (1989).

(Received May 30, 1991) (Accepted July 29, 1991) 